\title{
Step-by-step of ultrasound-guided core-needle biopsy of the breast: review and technique*
}

\author{
Passo-a-passo da core biópsia de mama guiada por ultrassonografia: revisão e técnica \\ Rafael Dahmer Rocha ${ }^{1}$, Renata Reis Pinto $^{2}$, Diogo Paes Barreto Aquino Tavares ${ }^{3}$, Cláudia \\ Sofia Aires Gonçalves ${ }^{4}$
}

\begin{abstract}
Ultrasound-guided core-needle biopsy has high sensitivity in the diagnosis of breast cancer. The present study is aimed at detailing the main steps of such procedure, including indications, advantages, limitations, follow-up and description of the technique, besides presenting a checklist including the critical steps required for an appropriate practice of the technique. In the recent years, an increasing number of patients have required breast biopsy, indicating the necessity of a proportional increase in the number of skilled professionals to carry out the procedures and histological diagnoses. A multidisciplinary approach involving the tripod clinical practice-radiology-pathology is responsible for the highest rate of accuracy of the technique and must always be adopted.
\end{abstract}

Keywords: Ultrasound-guided core-needle biopsy; Breast.

Resumo A core biópsia de mama guiada por ultrassonografia possui alta sensibilidade no diagnóstico das doenças neoplásicas mamárias. 0 presente estudo tem por objetivo detalhar as principais etapas deste procedimento, incluindo indicações, vantagens, limitações, seguimento e técnica, e elaborar um checklist contendo os passos indispensáveis para uma boa prática da técnica. 0 número de pacientes que necessitam de biópsia mamária tem crescido nos últimos anos, indicando ser necessário haver um crescimento proporcional de profissionais habilitados que possam realizar os procedimentos diagnósticos histológicos. A abordagem multidisciplinar envolvendo o triângulo clínica-radiologia-patologia é responsável pelo mais alto índice de acurácia da técnica, devendo sempre ser utilizada.

Unitermos: Core biópsia guiada por ultrassonografia; Mama.

Rocha RD, Pinto RR, Aquino D, Aires CS. Step-by-step of ultrasound-guided core-needle biopsy of the breast: review and technique. Radiol Bras. 2013 Jul/Ago;46(4):234-241.

\section{INTRODUCTION}

An increasing preoccupation has been demonstrated in the recent Brazilian radiological literature towards the importance of imaging studies in the improvement of breast diseases diagnosis ${ }^{(1-10)}$.

Over the last decades, imaging-guided percutaneous procedures have become very reliable options for histological diagnoses.

* Study developed at Hospital Federal dos Servidores do Estado do Rio de Janeiro and at Hospital do Instituto Nacional de Câncer (INCA), Rio de Janeiro, RJ, Brazil.

1. MD, Resident in Radiology and Diagnostic Imaging, Hospital Federal dos Servidores do Estado do Rio de Janeiro, Rio de Janeiro, RJ, Brazil.

2. MD, Mastologist, Hospital do Instituto Nacional de Câncer (INCA), Rio de Janeiro, RJ, Brazil.

3. Head of Interventional Radiology Department, Hospital Federal dos Servidores do Estado do Rio de Janeiro, Rio de Janeiro, RJ, Brazil.

4. MD, Radiologist, Hospital Federal dos Servidores do Estado do Rio de Janeiro, Rio de Janeiro, RJ, Brazil.

Mailing Address: Dr. Rafael Dahmer Rocha. Avenida XV de Novembro, 70, ap. 801, Centro. Joaçaba, SC, Brazil, 89600000. E-mail: rafaeldrocha@gmail.com.

Received September 2, 2012. Accepted after revision February 19, 2013.
Fine-needle aspiration biopsy (FNAB) was utilized for many years to investigate the breast tissue in the attempt to avoid surgical biopsy (gold standard). With the arrival of core biopsy, a better specimen quality could be obtained and it became possible to differentiate carcinomas in situ from invasive carcinomas.

In cases of breast lesions, core biopsy (CB) is preferably performed, utilizing an imaging method as guidance - for example: ultrasonography (US) or stereotactic biopsy -, but it is still performed, with lower sensitivity, only by means of palpation ${ }^{(11)}$. First described by Parker et al. ${ }^{(\mathbf{1 2})}$ in the early 1990's, US-guided CB of breast is currently one of the main diagnostic methods for neoplastic breast diseases, and for lesions that are sonographically visible, is frequently considered the procedure of choice $^{(\mathbf{1 2 - 2 3 )}}$.

The present study is aimed at detailing the main steps of US-guided CB of breast, including indications, advantages, limita- tions, follow-up and description of the technique, besides presenting a checklist including the critical steps required for an appropriate practice of such procedure.

\section{REVIEW}

The most consistent indications for USguided CB of breast are listed on Table 1. Patients with imaging studies revealing findings as BI-RADS ${ }^{\circledR}$ category 4 (approximately $20 \%$ to $40 \%$ are malignant $)^{(\mathbf{1 4 , 1 9 , 2 4 )}}$ or BI-RADS 5 (about $95 \%$ are malignant $)^{(25,26)}$ must undergo biopsy. Findings classified as BI-RADS 3 present a lower risk for malignancy $(<2.0 \%)$, but such findings do require short-term follow-up ${ }^{(25,26)}$ In such category, the following situations are indicative for biopsy: difficulty in performing the short-term follow-up (geographic factors, pregnancy, plastic breast surgery) or which may cause psychological constraint to the patient ${ }^{(\mathbf{1 4 , 1 9 , 2 4 )}}$; explicit will of the patient and/or assisting physician; 
Table 1 Indications for core breast biopsy according to the BI-RADS category of images (mammography, ultrasonography and magnetic resonance imaging).

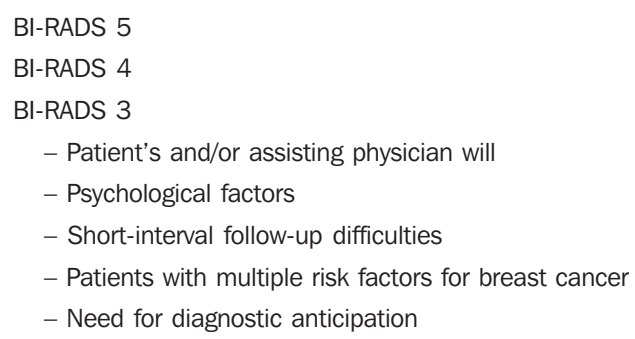

clinical situations requiring anticipation of diagnosis, as such situations that may cause therapeutic changes (for example: transplants, synchronous malignancy) ${ }^{(14,27)}$; and patients with multiple risk factors for breast cancer.

The sensitivity of US-guided CB of breast was reviewed by Youk et al. ${ }^{(15)}$ in eight studies involving a total of $1,518 \mathrm{pa}-$ tients, obtaining a mean rate of $96 \%$, similar to the rate obtained with surgical biopsy. Schueller et al. ${ }^{(28)}$ have also found similar sensitivity $(95.8 \%)$ in 1,352 cases. Some factors increase the sensitivity of the samples and should be taken into consideration: five as minimum number of specimens ${ }^{(12,17,23,29)}$ which ideally should be intact, homogeneous, predominantly white, and sinks as soon as it is put in the formaldehyde solution ${ }^{(15,24,29)}$; and obtained by a
CB device with appropriate depth range (> $15 \mathrm{~mm}$ ), so the sensitivity is directly proportional to the volume of specimens ${ }^{(12,13}$, ${ }^{24,29,30)}$. Some studies ${ }^{(13,15,20)}$ suggest that the real-time visualization of the needle within the lesion may help in reducing the number of false-negatives.

The US-guided CB of breast is better tolerated than surgical biopsy, and can be performed quickly and at a much lower cost, as demonstrated in Table 2. Over the past 20 years, the present technique has demonstrated to be very safe, with rare severe complications ${ }^{(11,12,19,31-33)}$. Parker et al. ${ }^{(21)}$ reported only six cases $(0.2 \%)$ in the follow-up of 3,765 CBs where the development of three voluminous hematomas and three abscesses was observed, requiring surgical drainage. No case of pneumothorax was observed in that study, de-
Table 2 Advantages and limitations of US-guided core biopsy of breast.

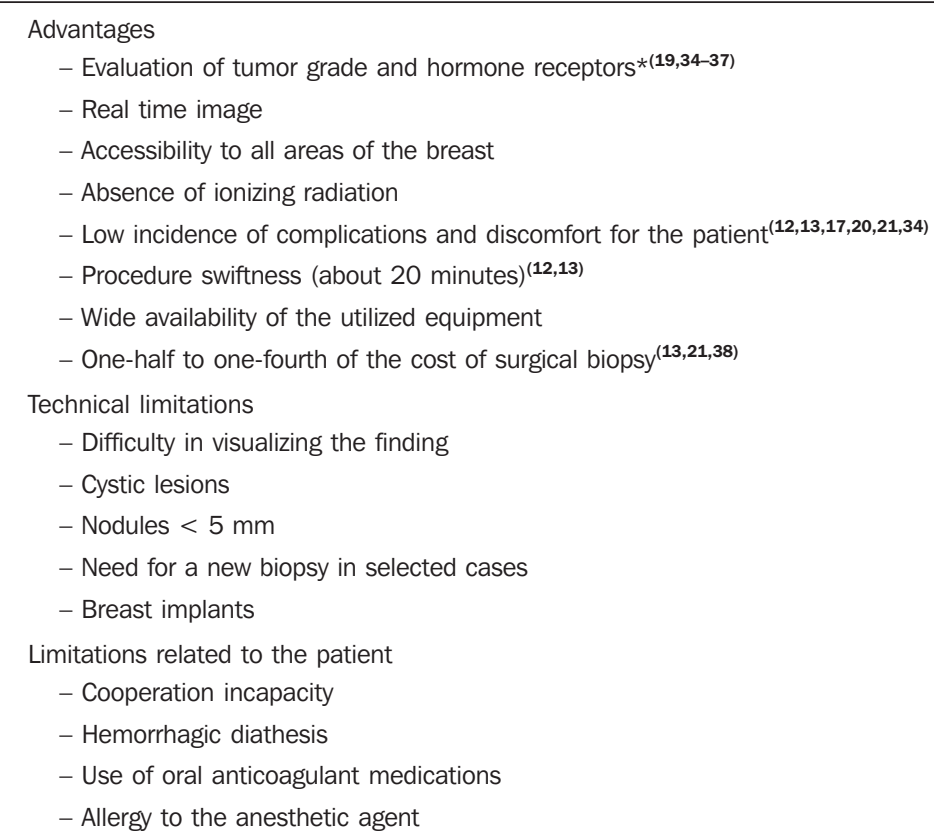

* Advantages over fine needle aspiration biopsy. spite the existence of some risk, which is higher in the cases of small breasts with axillary or medial lesions ${ }^{(39)}$. Fistulas may occur during pregnancy or lactation, particularly in central and deep regions of the breast $^{(\mathbf{1 9 , 3 1})}$. Minor complications such as pain, edema, psychological trauma, small hemorrhages and vasovagal reactions are frequently observed ${ }^{(12,27,31)}$. Hemorrhages are more frequent in hypertensive women and in breasts submitted to radiotherapy, whose vessels are more friable ${ }^{(40)}$. Whenever possible, biopsies should be avoided in the perimenstrual period, where the breasts are more sensitive.

As regards anticoagulant drugs, in spite of acetylsalicylic acid not being a contraindication ${ }^{(19,27,30)}$, LaTrenta recommends that its use should be avoided for seven days prior to the biopsy, as well as the interruption of non-steroidal anti-inflammatory drugs for 2-5 days ${ }^{(31)}$. As regards the decision of interrupting oral anticoagulant drugs, it should only be made after multidisciplinary analysis ${ }^{(\mathbf{1 9})}$, by pondering the risk for thrombotic events versus the risk for development of important hematoma. If such an interruption is considered necessary, its use may be stopped 4-7 days before the procedure, and resumed soon after the procedure ${ }^{(31)}$.

The rate of repeated biopsies reaches up to $18 \%$ of cases ${ }^{(11,18,40,41)}$. According to Liberman et al. ${ }^{(13)}$, nodules $<5$ mm may occasionally be completely removed during the biopsy procedure in $4 \%$ to $9 \%$ of cases, impairing the surgical marking. In such cases, the placement of a metal clip is suggested, to serve as a marker for later surgery. Memarsadeghi et al. ${ }^{(\mathbf{4 2})}$ have reported a $0.4 \%$ overall rate of false-negatives in a series of 3,380 biopsies. Among the factors which increase the false-negatives rate, the following factors were associated: poor needle visualization, lesion mobility, deep lesions, central lesions in large breasts, dense breast with fibrosis, nodules $\leq 5 \mathrm{~mm}$, and lesions obscured by blood accumulation. In other study, the false-negative rate was $1.1 \%$, and more than $20 \%$ of the biopsied lesions measured up to $10 \mathrm{~mm}^{(\mathbf{2 1})}$. Fornage et al. ${ }^{(\mathbf{4 3})}$ have reported that any lesion clearly visualized at US can be submitted to CB.

Despite the innumerable advantages of utilizing US-guided biopsy, some lesions 
are not visible at the method, and in such cases the utilization of stereotactic biopsy is preferable ${ }^{(14,17,31,44)}$. Patients with suspicious microcalcifications or with breast implants may benefit from vacuum-assisted biopsy, because of the higher number of calcifications in the specimens and lower

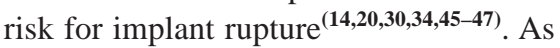
regards simple cystic lesions, FNAB, besides being a diagnostic method may also become therapeutic as the cytological aspirate is typically benign.

\section{PRE-BIOPSY (PATIENT, ROOM AND MATERIAL)}

Because of the low incidence of complications and contraindications, generally no laboratory test is required, except for those patients with a history of coagulopathy or under anticoagulant ion therapy $^{(2,19,23,31)}$. Routine prophylactic antibiotics are not indicated, but the sterile technique should be used, minimizing post-biopsy infections $^{(31)}$. Bugbee et al. ${ }^{(48)}$ have evaluated the effects of pre-biopsy oral anxiolytic medication and found a significant reduction in the anxiety levels in the women group that utilized $0.25-0.5 \mathrm{mg}$ alprazolam 15 minutes before the procedure.

The room must be appropriate for the performance of the procedure, with adjustable lighting and circulation area at both sides of the table, in order to facilitate the assistant's movements and access to all regions of the breast and axilla. The transducer must be of high-frequency (ideally higher than $10 \mathrm{MHz}$ ) linear type ${ }^{(15)}$, and must be cleaned with antiseptics or be involved by a cover or a sterile glove ${ }^{(\mathbf{1 2})}$. Sterile gel or the antiseptic itself will serve as ultrasound conductive agent.

An automated biopsy device equipped with a long needle (reaching $23 \mathrm{~mm}$ ) is preferable over the short needle (reaching $15 \mathrm{~mm}$ ). The recommended needle caliber for CB is 14-gauge, which has demonstrated greater sensitivity than the 16gauge and 18-gauge needles, without increasing complications or costs ${ }^{(27,34,35,49-}$ 51). The professional must be experienced in manipulating the $\mathrm{CB}$ device and also be aware on how many millimeters the needle will advance when the device is triggered, in order to avoid transfixion of the chest wall.

Before initiating the procedure itself, some items must be checked out. The patient must be duly explained on the reason for the biopsy, the technique that will be utilized, the risks and benefits, and on the existence of alternative techniques. A term of free and informed consent should then be signed by the patient. Previous images should be reviewed, and then an US scan should be performed to document the lesion and establish the technique to be utilized, confirm whether the indication for biopsy is appropriate and evaluate limitations which may negatively impact the procedure. The lesion documentation will be useful for follow-up and comparison purposes. Orthogonal measurements and localization of the lesion must be performed (the clock position system is recommended and the distance between the lesion and the nipple should be measured and recorded). At that point, the physician should establish the best pathway to reach the lesion, and decide which hand he will use to hold the transducer. The choice must lie on the one which will provide greater comfort and effectiveness for the procedure, and may vary according to the lesion site and to the dominant hand of the professional.
The patient is usually positioned in dorsal decubitus, with the upper limb ipsilateral to the lesion being rested behind her

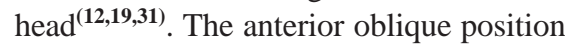
may be beneficial in patients with large breasts or extreme lateral lesion location $^{(19,31)}$. Lesions located in the outer quadrant are usually better approached with the professional positioned at the side of the ipsilateral breast, while in lesions located in the inner quadrant the professional should be positioned at the side of the contralateral breast ${ }^{(31)}$.

A sterile surgical drape should be placed on a portable table and the materials represented on Figure 1 should be positioned over that drape. The physician puts on the sterile gloves and couples the biopsy needle to the $\mathrm{CB}$ device. He then performs a triggering test, informing the patient that the clicking sound will be heard each time a sample is obtained. In cases of very dense breasts, the physician should pay special attention to the clicking sound, as when it sounds differently than expected, this may mean that the sample is inappropriate. Subsequently, the anesthetic agent is aspirated into a syringe with $5-10 \mathrm{ml}$ of lidocaine $1 \%$ (without vasoconstrictor), or 3-5 $\mathrm{ml}$ of lidocaine $2 \%$ diluted in $5 \mathrm{ml}$ distilled water.

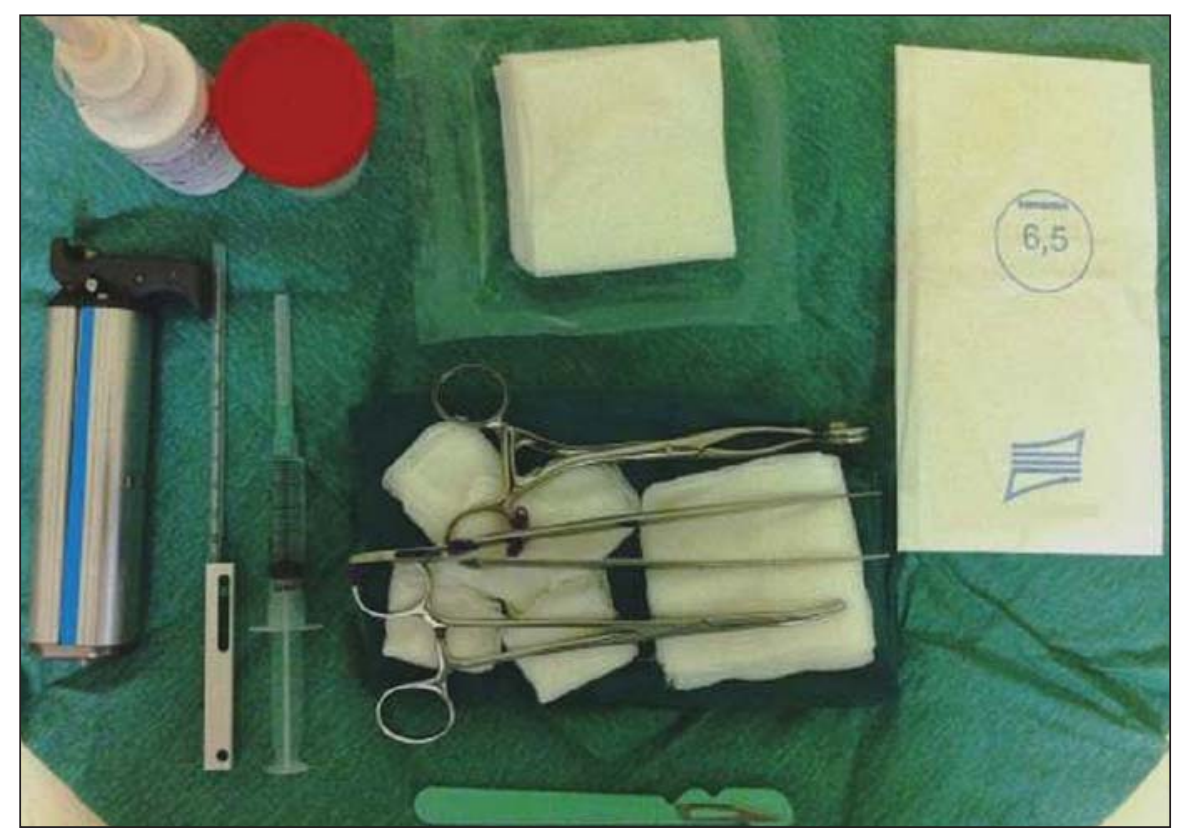

Figure 1. Arrangement of materials required for the performance of core biopsy of breast. Fenestrated surgical drape, scalpel blade, 18-gauge to 22-gauge needles, 5-10 ml syringe, vial with 5-10 ml of 10\% formalin, sterile gloves and gauze pads, automated core biopsy device and 14-gauge core biopsy needle. 


\section{BIOPSY}

The preferred biopsy technique is the "freehand" technique based on the description by Parker et al. ${ }^{(\mathbf{1 2})}$ and by other authors ${ }^{(19,31,34,52)}$, where the radiologist manipulates the transducer with one hand and the $\mathrm{CB}$ device with the other. As regards technical standards, there are small regional variations. On Table 3, a checklist is suggested, adapted from the literature review and from the authors' own professional experience.

Figure 2 shows the main steps at USguided breast CB. Initially, the antisepsis of the exposed area is performed by means of sterile gauze pad and antiseptic solution (chlorhexidine, povidone iodine or alcohol). The lesion to be biopsied is identified with the transducer and, it is recommended that with the palm of the same hand, the fourth and fifth fingers resting on the field without exerting pressure on the breast the physician avoids the motion of the breast. By keeping the area of interest farther from the needle insertion point, it is possible to observe its entire trajectory, from the skin surface up to the lesion.

The recommended access area is the peripheral curvature of the breast, positioning the needle at 2 to $3 \mathrm{~cm}$ away from the edge of the transducer, in parallel to the chest wall and perpendicularly to the transducer, allowing a better US visualization of the needle and reducing the risk for pneumothorax (Figure 3A). The access through the nipple-areolar complex should be avoided. In cases of very deep or centrally and superficially located lesions, the oblique needle access may be necessary, which may impair its visualization at US. In such cases, the transducer should be angled at approximately $90^{\circ}$ (Figure 3B).

Under US guidance, the anesthetic agent is infiltrated along the pathway of the

Table 3 Checklist for US-guided core biopsy of breast.

1. Review previous imaging studies and perform a well documented targeted ultrasonography scan.

2. Evaluate whether the biopsy is appropriately indicated and its limitations (Tables 1 and 2).

3. Obtain the term of free and informed consent from the patient after having explained its entire contents.

4. Define the pathway to approach the lesion, as well as which of the physician's hands will be used for each function.

5. Carry out the antisepsis of the transducer and prepare the materials on a portable table.

6. Don the sterile gloves and couple the core biopsy needle $(14 \mathrm{G})$ to the device. Perform a triggering test, checking out the needle travel, as well as the triggering sound from the device.

7. Aspirate the anesthetic agent (1-2\% lidocaine without vasoconstrictor).

8. Positioning the patient (usually in dorsal or anterior oblique decubitus).

9. Perform the antisepsis over a wide area around the lesion, over which a sterile fenestrated drape should be placed. The antiseptic or sterile gel will serve as an ultrasound conductive agent.

10. Sonographically identify the lesion. The palm of the hand holding the transducer and the fourth and fifth fingers exert some pressure on the breast to avoid its motion.

11. Remember the access and entry point defined on item 4. Under US guidance, inject the anesthetic agent through the entire pathway up to the lesion.

12. Make a 2-3 $\mathrm{mm}$ incision on the skin over needle entry point.

13. Insert the biopsy needle through the incision, attempting to follow the same pathway of the anesthetic needle towards the lesion border. At this point, the needle is to be directed to a position parallel to the nodule.

14. Tell the patient that a sample is about to be obtained, and trigger the device action.

15. Cross sectionally and longitudinally slide the transducer aiming at verifying whether the needle penetrated the nodule and that no injury occurred to the chest wall.

16. Retrieve the sample from the needle with the scalpel blade or sterile needle, placing it in the vial with formaldehyde, briefly evaluating its characteristics.

17. Repeat steps 13 to 16 until a minimum of five good samples are obtained, preferably from different areas of the lesion (center, $3,6,9$, and 12 o'clock positions). In cases of microcalcifications, at least ten samples should be collected and submitted to radiography, identifying and separating those without calcifications from the ones with calcium.

18. Compress the lesion and incision areas for at least five minutes and apply local ice.

19. Perform asepsis and apply compressive dressings which should be left in place for 24-48 hours.

20. Instruct the patient to avoid intense physical exertion and prescribe pain-relievers and non-steroid anti-inflammatory medication, as necessary.

21. Clarify doubts and schedule return as soon as the histopathological results are available. The approach should be adopted according to Table 4 .

* Note: The presence of an assistant is valuable during the procedure. Such an assistant can perform the functions described on items 5 , 8, 9, 16,18 and 19. This will make the procedure swifter and the physician will be able to exert compression on the breast after triggering the CB device, thus decreasing the risk for development of hematoma.

Table 4 Radiological-pathological correlation of core biopsy of breast.

\begin{tabular}{llll}
\hline Classification & Radiological result & Histological result & Recommended approach \\
\hline Concordant benign results & BI-RADS 3 or 4 & Benign lesions & Six-month imaging follow-up \\
Discordant benign results & BI-RADS 5 & Benign lesions & Surgical biopsy \\
$\begin{array}{l}\text { Risk lesions, precursor lesions, } \\
\text { or lesion at risk for underesti- } \\
\text { mation }\end{array}$ & Independent & $\begin{array}{l}\text { Carcinoma in situ, radial scar, atypical epithelial prolif- } \\
\text { eration, lobular neoplasias, papilliferous lesions, fibroepi- }\end{array}$ & Surgical biopsy \\
Malignant & thelial lesion (with possibility of phyllodes tumor) & Contact assisting physician
\end{tabular}



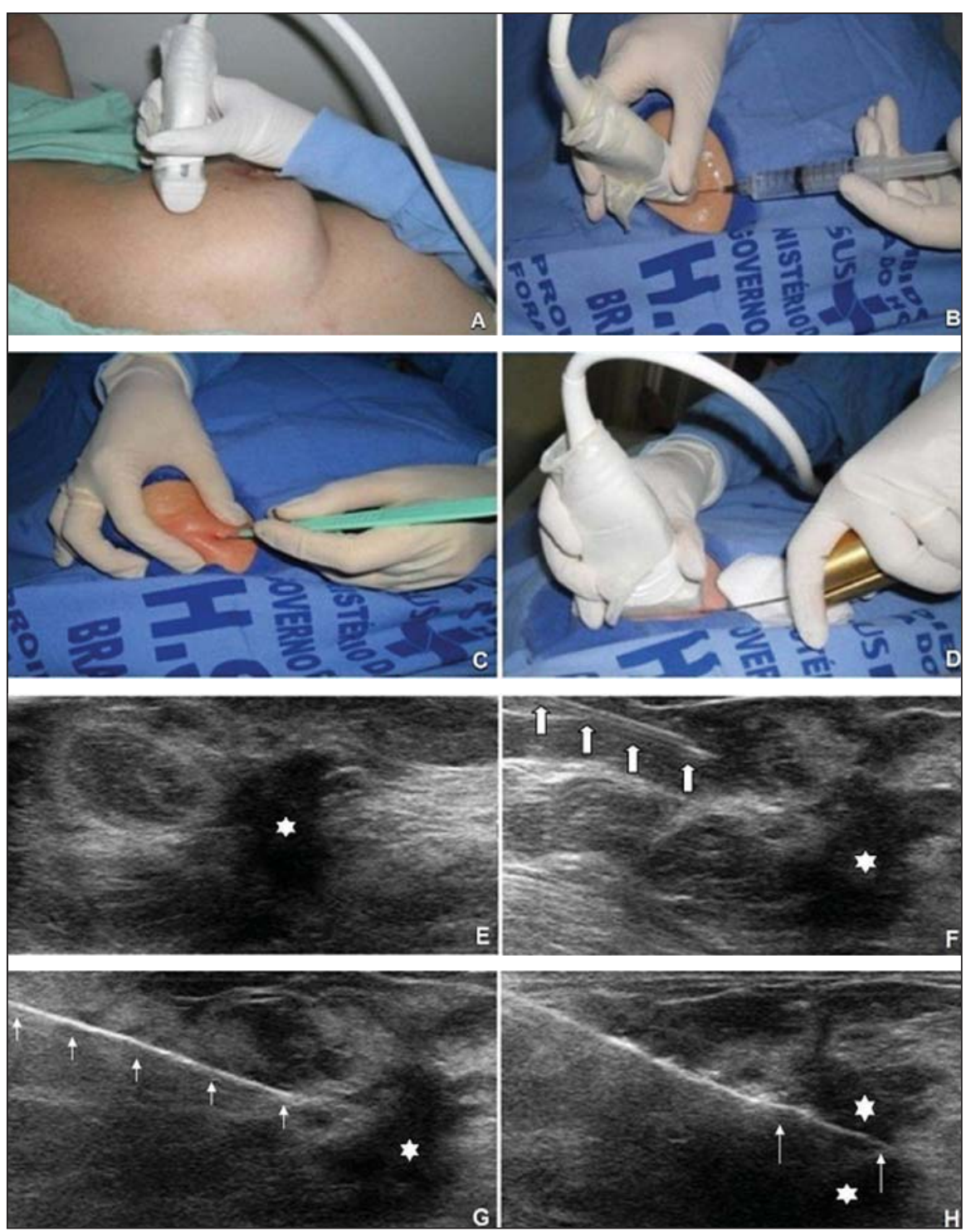

Figure 2. Main steps of ultrasonography-guided core biopsy of breast. A and E: Identification of the suspicious lesion (asterisk). B and F: Infiltration of the anesthetic though the pathway up to the lesion. The anesthetic needle is visualized as a fine hyperechogenic line (wide arrows). C: $2-3 \mathrm{~mm}$ incision on the numbed area. D and G: Through the incision, the same pathway utilized for anesthesia is utilized for in sertion of the core needle (thin arrows) up to the lesion border. $\mathbf{H}$ : Once the CB devise is triggered, one must check whether the needle penetrated the lesion (asterisks). It is possible to observe the segment of the needle which advanced over the nodule (space between arrows). needle up to the lesion. In cases of mobile lesions, the infiltration can be performed in the lesions' circumjacent areas, which will reduce its mobility. Deep lesions may benefit from posterior anesthetic infiltration, in an attempt to displace the nodule anteriorly.

With a scalpel blade, a 2-3 mm incision is made on the numbed skin. Gauze pads are to be left in the incision proximity, in order to facilitate breast compression and cleaning of blood. Though the incision location, the biopsy needle is advanced towards the lesion's margin, through the same pathway utilized for anesthesia. The needle is positioned parallel to the nodule, the patient is warned that the sample is about to be collected, and the CB device is triggered.

In cases of mobile lesions, with the same hand that holds the transducer, pressure can be exerted against the nodule, thus decreasing the possibility of the needle pushing the nodule backwards as the device is triggered, so the collected sample is inappropriate. It is also possible to push the tip of needle into the nodule prior to triggering the $\mathrm{CB}$ device. Deep lesions may be better accessed with a greater needle angulation to reach the posterior border of the lesion. The needle may be directed upwards with the purpose of lifting the lesion and moving it away as much as possible from the chest wall (Figure 3C). An important difficulty may be observed in patients very dense breasts. In such cases, breast fibrosis may impair the progression of the needle and repeating the trajectory after each triggering represents an important limitation. Thus the technique with coaxial needle should be utilized, allowing for different areas to be biopsied by just changing the angle of the trocar.

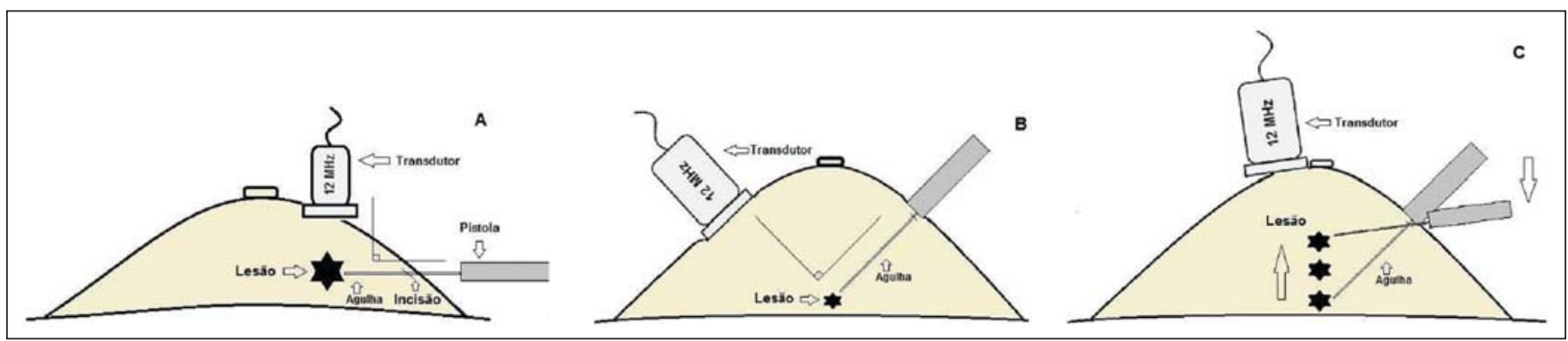

Figure 3. Commonly utilized approaches at US-guided core biopsy of breast. A: Needle parallel to the chest wall, perpendicular to the transducer. Better sonographic visualization of the needle and lower risk for pneumothorax. B: Needle angulated in relation to the chest wall. The transducer is guided in an attempt to maintain a perpendicular angle. Useful in very deep or superficial central lesions. C: The inferior movement of the CB device may help to move the lesion away as much as possible from the chest wall. 


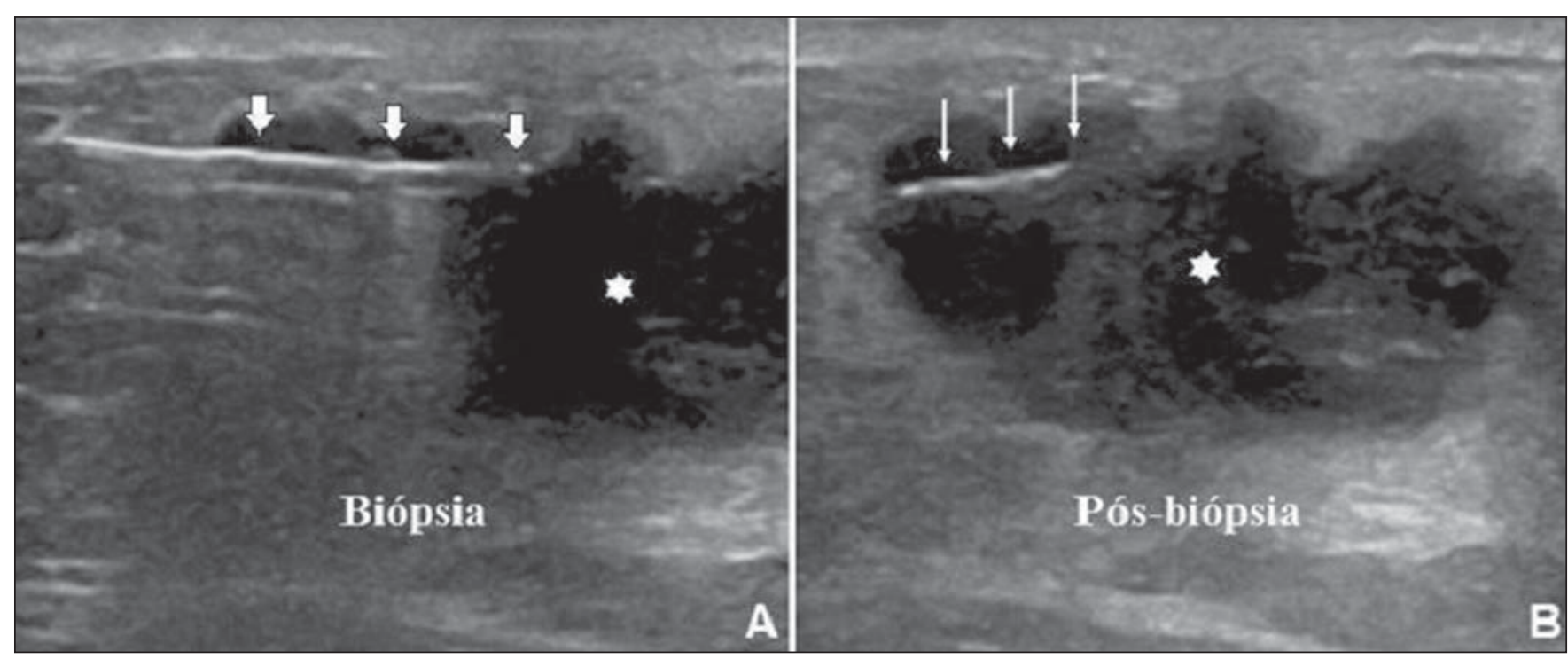

Figure 4. Post-triggering air artifact. A: Needle path (wide arrows) within the nodule (asterisk) during biopsy. B: After biopsy, a small amount of gas can be observed, represented by a hyperechogenic line (thin arrows). Such artifact may be useful in the determination of lesion locations yet to be biopsied.

Once the device is triggered, the operator must sonographically confirm whether the needle is inside the nodule, by analyzing the needle in the two planes (cross sectional and longitudinal). Frequently during the biopsy, air enters through the needle and is visualized as a hyperechoic line in the triggering trajectory (Figure 4). Such artifact may be useful in the determination of lesion locations yet to be biopsied.

The lesion sample must be retrieved from the core needle and be briefly analyzed with respect to the characteristics which classify such sample as appropriate (Figure 5). The anesthetic needle or the scalpel may be utilized to retrieve the sample, and place it in a vial containing $10 \%$ formalin. Samples should be obtained from different areas of the lesion, usually from the center and close to the borders at the 3, 6, 9 and 12 o'clock positions. Between each and other consecutive sample retrieval, the physician or the assistant must compress the breast with gauze pads in order to reduce the risk for hematomas. In those biopsies including microcalcifications, Parker et al. ${ }^{(\mathbf{1 2})}$ recommend collecting at least 10 samples, which should be submitted to radiography to confirm the presence or absence of calcium ${ }^{(\mathbf{5 0})}$. It is recommended that samples containing calcifications be separated from those without calcification when they are sent for histopathological analysis.

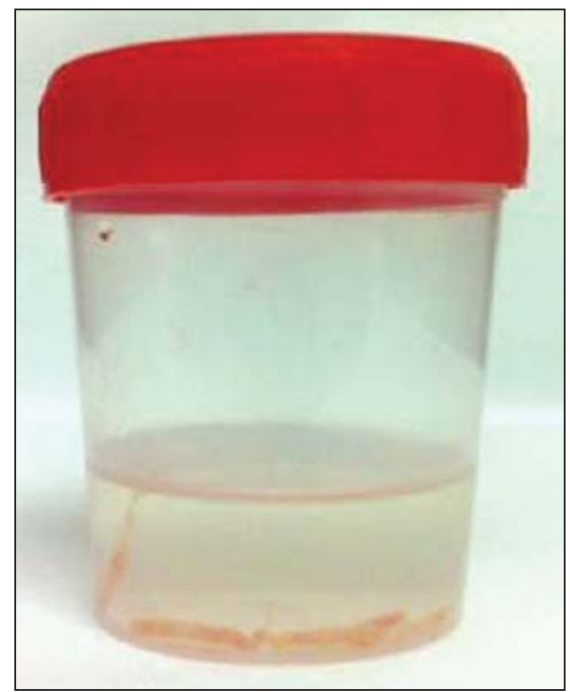

Figure 5. Appropriate specimens of breast core biopsy: predominantly white, integral and sinks in the solution.

\section{POST-BIOPSY PROCEDURES}

Once the samples are obtained, the areas of the incision and of the nodule are compressed for at least five minutes, and a dressing is then applied. The utilization of ice on the biopsy site may also help in hemostasis. The patient is requested to avoid more intense physical exertion for at least two days. Pain relieving and anti-inflammatory medications are prescribed as necessary, avoiding the utilization of acetylsalicylic acid for seven days after the pro- cedure. The professional then issues a procedure report and fills out a histopathological analysis request with a detailed report on the lesion, specifying radiological category, location, number of collected samples, presence of lymph node enlargement and occurrence of possible complications. Any patient's doubts should be clarified, and a return should be scheduled upon availability of the histopathological results.

The follow-up recommended by Youk et al. ${ }^{(15)}$ and by the Instituto Nacional de Câncer ${ }^{(\mathbf{5 1})}$ is shown on Table 4. It is extremely important to be aware of the histological results and to maintain a close follow-up on the patient, so that in the event of discordant results, particularly in those cases where the possibility of malignancy is underestimated, a correct diagnosis may be obtained as early as possible. A good physician-patient relationship as well as a good relationship with the pathologist must be emphasized. In two studies ${ }^{(\mathbf{1 8 , 2 2})}$, a great part of the false-negatives could be reevaluated soon enough, without changes in patient progression. Liberman ${ }^{(\mathbf{5 2})}$ has reviewed some studies and found rates of $20 \%$ to $56 \%$ of underestimated carcinomas in atypical ductal hyperplasia and of $16 \%$ to $35 \%$ in ductal carcinomas in situ. Underestimated lesions are those whose surgical biopsy revealed ductal carcinoma in situ or invasive ductal carcinoma, while at CB the result indicated high risk lesion or carci- 
noma, but with incomplete pathological characterization $^{(\mathbf{1 6}, 40,53)}$. Some studies have demonstrated that the utilization of vacuum-assisted biopsy reduced the risk for underestimation in cases of atypical ductal hyperplasia and ductal carcinoma in situ by $20 \%$ and $10 \%$, respectively ${ }^{(\mathbf{3 0}, 54)}$.

As regards rebiopsy incidence, Youk et al. ${ }^{(15)}$ have found a rate of $10 \%$ (338 patients) in 3,299 biopsied lesions in eight studies, from which $17 \%$ were malignant lesions. Main reasons for rebiopsy were histology results demonstrating benign lesions and/or high risk lesions requiring sur-

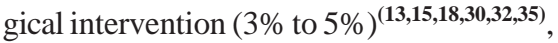
followed by results in disagreement with clinico-radiological findings (2\% to $7.7 \%$ of the total $)^{(\mathbf{1 5 , 1 9 , 4 0 )}}$ and inappropriate samples

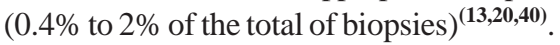

\section{CONCLUSION}

The number of patients who require breast biopsy has increased over the past years, mainly because of wider access of the population to breast cancer screening allowing earlier diagnosis. Thus, a proportional or greater increase in the number of professionals who perform histological diagnoses is necessary in order to reduce the wait for a definitive diagnosis and increase the patients' survival. Ultrasonography-guided core biopsy of breast has become the method of choice for all alterations visualized at the method, with sensitivity rates which are very close to those of surgical biopsy. A multidisciplinary approach involving the tripod clinical practice-radiology-pathology is responsible for the highest rate of accuracy of the technique and must always be adopted. Finally, the radiologist also plays an important role in the follow-up of such patients, with whom a sound relationship must be maintained in order to guarantee the patients' return and appropriate follow-up.

\section{REFERENCES}

1. Miranda CM, Santos CJ, Maranhão CP, et al. A tomografia computadorizada multislice é ferramenta importante para o estadiamento e seguimento do câncer de mama? Radiol Bras. 2012;45: 105-12.

2. Calas MJ, Gutfilen B, Pereira W. CAD e mamografia: por que usar esta ferramenta? Radiol Bras. 2012;45:46-52.

3. Azevedo A, Canella E, Djahjah MC, et al. Con- duta das funcionárias de um hospital na adesão ao programa de prevenção do câncer de mama. Radiol Bras. 2012;45:215-8.

4. Alvares B, Freitas C, Jales R, et al. Mammographic density in asymptomatic menopausal women: correlation with clinical and sonographic findings. Radiol Bras. 2012;45:149-54

5. Barra FR, Barra RR, Barra Sobrinho A. Novos métodos funcionais na avaliação de lesões mamárias. Radiol Bras. 2012;45:340-4.

6. Criado DA, Braojos F, Torres U, et al. Aesthetic breast augmentation with hyaluronic acid: imaging findings and implications for radiological assessment. Radiol Bras. 2012;45:181-3.

7. Urban L, Schaefer M, Duarte D, et al. Recomendações do Colégio Brasileiro de Radiologia e Diagnóstico por Imagem, da Sociedade Brasileira de Mastologia e da Federação Brasileira das Associações de Ginecologia e Obstetrícia para rastreamento do câncer de mama por métodos de imagem. Radiol Bras. 2012;45:334-9.

8. Calas MJG, Alvarenga AV, Gutfilen B, et al. Avaliação de parâmetros morfométricos calculados a partir do contorno de lesões de mama em ultrassonografias na distinção das categorias do sistema BI-RADS ${ }^{\circledR}$. Radiol Bras. 2011;44:289-96.

9. Marques E, Medeiros ML, Souza J, et al. Indicações de ressonância magnética das mamas em um centro de referência em oncologia. Radiol Bras. 2012;44:363-6.

10. Lykawka R, Biasi P, Guerini C, et al. Avaliação dos diferentes métodos de medida de força de compressão em três equipamentos mamográficos diferentes. Radiol Bras. 2012;44:172-6.

11. Liberman L, Ernberg LA, Heerdt A, et al. Palpable breast masses: is there a role for percutaneous imaging-guided core biopsy? AJR Am J Roentgenol. 2000;175:779-87

12. Parker SH, Jobe WE, Dennis MA, et al. USguided automated large-core breast biopsy. Radiology. 1993;187:507-11.

13. Liberman L, Feng TL, Dershaw DD, et al. US guided core breast biopsy: use and cost-effectiveness. Radiology. 1998;208:717-23.

14. Liberman L. Centennial dissertation. Percutaneous imaging-guided core breast biopsy: state of the art at the millennium. AJR Am J Roentgenol. 2000;174:1191-9.

15. Youk JH, Kim EK, Kim MJ, et al. Missed breast cancers at US-guided core needle biopsy: how to reduce them. Radiographics. 2007;27:79-94.

16. Youk JH, Kim EK, Kim MJ, et al. Sonographically guided 14-gauge core needle biopsy of breast masses: a review of 2,420 cases with long-term follow-up. AJR Am J Roentgenol. 2008;190:2027

17. Dillon MF, Hill AD, Quinn CM, et al. The accuracy of ultrasound, stereotactic, and clinical core biopsies in the diagnosis of breast cancer, with an analysis of false-negative cases. Ann Surg. 2005 242:701-7.

18. Schoonjans JM, Brem RF. Fourteen-gauge ultrasonographically guided large-core needle biopsy of breast masses. J Ultrasound Med 2001;20:967-72

19. Harvey JA, Moran RE. US-guided core needle biopsy of the breast: technique and pitfalls. Radiographics. 1998;18:867-77.

20. Philpotts LE, Hooley RJ, Lee CH. Comparison of automated versus vacuum-assisted biopsy methods for sonographically guided core biopsy of the breast. AJR Am J Roentgenol. 2003;180:347-51.

21. Parker SH, Burbank F, Jackman RJ, et al. Percutaneous large-core breast biopsy: a multi-institutional study. Radiology. 1994;193:359-64.

22. Crystal P, Koretz M, Shcharynsky S, et al. Accuracy of sonographically guided 14-gauge coreneedle biopsy: results of 715 consecutive breast biopsies with at least two-year follow-up of benign lesions. J Clin Ultrasound. 2005;33:47-52.

23. Liberman L, Dershaw DD, Rosen PP, et al. Stereotaxic 14-gauge breast biopsy: how many core biopsy specimens are needed? Radiology. 1994; 192:793-5.

24. Dershaw DD. Needles and biopsy probes. In: Dershaw DD, editor. Imaging-guided interventional breast techniques. New York: SpringerVerlag; 2003. p. 69-86.

25. American College of Radiology. BI-RADS® Ultrasound, 1st ed. Breast Imaging Reporting and Data System Atlas (BI-RADS® Atlas). 4th ed Reston: American College of Radiology; 2003.

26. American College of Radiology. BI-RADS® Mammography, 4th ed. Breast Imaging Reporting and Data System Atlas (BI-RADS $®$ Atlas) 4th ed. Reston: American College of Radiology; 2003.

27. Sweeney KJ, Kerin MJ. Preoperative diagnosis and biopsy guns. In: Drew P, Cawthorn S, Michell $\mathrm{M}$, editors. Interventional ultrasound of the breast. London: Informa Healthcare; 2007. p. 63-78.

28. Schueller G, Jaromi S, Ponhold L, et al. US-guided 14-gauge core-needle breast biopsy: results of a validation study in 1352 cases. Radiology. 2008; 248:406-13.

29. Fishman JE, Milikowski C, Ramsinghani R, et al US-guided core-needle biopsy of the breast: how many specimens are necessary? Radiology. 2003 226:779-82.

30. Mainiero MB, Koelliker SL, Lazarus E, et al. Ultrasound-guided large-core needle biopsy of the breast: frequency and results of repeat biopsy. J Women Imaging. 2002;4:52-7.

31. LaTrenta L. Ultrasound-guided core breast biopsy. In: Dershaw DD, editor. Imaging-guided interventional breast techniques. New York: SpringerVerlag; 2003. p. 119-29.

32. Sauer G, Deissler H, Strunz K, et al. Ultrasoundguided large-core needle biopsies of breast lesions: analysis of 962 cases to determine the number of samples for reliable tumour classification. Br J Cancer. 2005;92:231-5.

33. Buchberger W, Niehoff A, Obrist P, et al. Sonographically guided core needle biopsy of the breast: technique, accuracy and indications. Radiologe. 2002;42:25-32.

34. Non-operative Diagnosis Subgroup of the National Coordination Group for Breast Screening Pathology. Guidelines for non-operative diagnostic procedures and reporting in breast cancer screening. NHSBSP Publication No. 50. Sheffield: NHS Cancer Screening Programmes; 2001.

35. Wallis M, Tarvidon A, Helbich T, et al. Guidelines from the European Society of Breast Imaging for diagnostic interventional breast procedures. Eur Radiol. 2007;17:581-8.

36. Verkooijen HM, Peeters PH, Buskens E, et al. Diagnostic accuracy of large-core needle biopsy for 
nonpalpable breast disease: a meta-analysis. Br J Cancer. 2000;82:1017-21.

37. Helbich TH, Matzek W, Fuchsjäger MH. Stereotactic and ultrasound-guided breast biopsy. Eur Radiol. 2004;14:383-93.

38. Burkhardt JH, Sunshine JH. Core-needle and surgical breast biopsy: comparison of three methods of assessing cost. Radiology. 1999;212:181-8.

39. Michell M. Tecnhiques of ultrasound biopsy. In: Drew P, Cawthorn S, Michell M, editors. Interventional ultrasound of the breast. London: Informa Healthcare; 2007. p. 79-88.

40. Berg WA. Image-guided breast biopsy and management of high-risk lesions. Radiol Clin North Am. 2004;42:935-46.

41. Gur D, Wallace LP, Klym AH, et al. Trends in recall, biopsy, and positive biopsy rates for screening mammography in an academic practice. Radiology. 2005;235:396-401.

42. Memarsadeghi M, Pfarl G, Riedl C, et al. Value of 14-gauge ultrasound-guided large-core needle biopsy of breast lesions: own results in comparison with the literature. Rofo. 2003;175: 374-80.

43. Fornage BD, Sneige N, Edeiken BS. Interventional breast sonography. Eur J Radiol. 2002; 42:17-31.
44. Liberman L. Stereotatic core biopsy. In: Dershaw $\mathrm{DD}$, editor. Imaging-guided interventional breast techniques. New York: Springer-Verlag; 2003. p. 87-118.

45. Liberman L, Drotman M, Morris EA, et al. Imaging-histologic discordance at percutaneous breas biopsy. Cancer. 2000;89:2538-46.

46. Brennan ME, Turner RM, Ciatto S, et al. Ductal carcinoma in situ at core-needle biopsy: metaanalysis of underestimation and predictors of invasive breast cancer. Radiology. 2011;260:11928

47. Jackman RJ, Lamm RL. Stereotactic histologic biopsy in breasts with implants. Radiology. 2002; 222:157-64

48. Bugbee ME, Wellisch DK, Arnott IM, et al. Breas core-needle biopsy: clinical trial of relaxation technique versus medication versus no intervention for anxiety reduction. Radiology. 2005;234 73-8

49. Nath ME, Robinson TM, Tobon H, et al. Automated large-core needle biopsy of surgically removed breast lesions: comparison of samples obtained with 14-, 16-, and 18-gauge needles. Radiology. 1995;197:739-42.

50. Pijnappel RM, van den Donk M, Holland R, et al.
Diagnostic accuracy for different strategies of image-guided breast intervention in cases of nonpalpable breast lesions. Br J Cancer. 2004;90: 595-600.

51. Helbich TH, Rudas M, Haitel A, et al. Evaluation of needle size for breast biopsy: comparison of 14-, 16-, and 18-gauge biopsy needles. AJR Am J Roentgenol. 1998;171:59-63.

52. Georgian-Smith D, Shiels WE 2nd. From the RSNA refresher courses. Freehand interventional sonography in the breast: basic principles and clinical applications. Radiographics. 1996;16: 149-61.

53. Liberman L, Kaplan JB, Morris EA, et al. To excise or to sample the mammographic target: what is the goal of stereotactic 11-gauge vacuum-assisted breast biopsy? AJR Am J Roentgenol. 2002;179:679-83.

54. Ministério da Saúde. Instituto Nacional de Câncer. Controle do câncer de mama: documento de consenso. Rio de Janeiro: Instituto Nacional de Câncer; 2004.

55. Liberman L. Percutaneous image-guided core breast biopsy. Radiol Clin North Am. 2002;40: 483-500. 